\title{
EFEKTIVITAS KEBIJAKAN SUBSIDI PUPUK DI DESA SUKAASIH KECAMATAN SUKATANI KABUPATEN BEKASI
}

\section{EFFECTIVENESS OF FERTILIZER SUBSIDIES IN SUKAASIH VILLAGE SUKATANI DISTRICT BEKASI REGENCY}

\author{
Prasaktiyoga Adiraputra*, Dika Supyandi \\ Universitas Padjadjaran, Jalan. Raya Bandung-Sumedang KM. 21, Jawa Barat 45363 \\ *Email: prasaktiyoga@gmail.com
}

(Diterima 7-1-2021; Disetujui 18-1-2021)

\begin{abstract}
ABSTRAK
Pemerintah telah mengeluarkan banyak dana untuk subsidi pupuk. Namun, dari hasil berbagai penelitian masih terdapat banyak masalah dalam implementasinya. Oleh karena itu, penelitian untuk mengetahui efektivitas subsidi pupuk menarik untuk dilakukan. Penelitian ini bertujuan untuk mengetahui efektivitas pelaksanaan subsidi pupuk. Penelitian ini dilaksanakan di Desa Sukaasih, Kecamatan Sukatani, Kabupaten Bekasi. Sampel penelitian ditentukan dengan metode multistage sampling yang menghasilkan sampel berjumlah 109 petani. Data yang telah didapatkan dianalisis menggunakan analisis distribusi frekuensi. Hasil penelitian diperoleh hasil bahwa pelaksanaan kebijakan subsidi pupuk di Desa Sukaasih tidak efektif. Oleh karena itu, pemerintah perlu memastikan percepatan dan mitigasi hambatan implementasi kartu tani di daerah dapat menjadi solusi agar subsidi pupuk dapat efektif.
\end{abstract}

Kata kunci: Efektivitas, subsidi pupuk, harga eceran tertinggi

\section{ABSTRACT}

The government has spent a lot of money on fertilizer subsidies. However, from the results of various studies, there are still many problems in its implementation. Therefore, research to determine the effectiveness of fertilizer subsidies is interesting. This study aims to determine the effectiveness of the implementation of fertilizer subsidies. This research was conducted in Sukaasih Village, Sukatani District, Bekasi Regency. The research sample was determined by the multistage sampling method which resulted in a sample of 109 farmers. The data that has been obtained were analyzed using frequency distribution analysis. The results showed that the implementation of the fertilizer subsidy policy in Sukaasih Village was not effective. Therefore, the government needs to ensure the acceleration and mitigation of barriers to implementing farmer cards in the regions can be a solution so that fertilizer subsidies can be effective.

Keywords: Effectiveness, fertilizer subsidy, higher retail price

\section{PENDAHULUAN}

$$
\text { Kebijakan subsidi pupuk }
$$

mengalami pro dan kontra dari tahun ke tahun. Di satu sisi, pemerintah masih bertahan dengan kebijakan subsidi pupuk untuk mempertahankan ketahanan pangan dengan menjaga tingkat produksi.
Produksi dapat dijaga untuk dapat memenuhi kebutuhan pangan dengan memberikan input yang baik, salah satunya pupuk. Pemanfaatan pupuk yang memadai baik dalam jumlah, kualitas dan kontinuitasnya diperlukan untuk mengurangi kemunduran kesuburan tanah 


\section{EFEKTIVITAS KEBIJAKAN SUBSIDI PUPUK DI DESA SUKAASIH \\ KECAMATAN SUKATANI KABUPATEN BEKASI \\ Prasaktiyoga Adiraputra, Dika Supyandi}

dan meningkatkan produktivitas yang berkelanjutan (Hartatik, et al, 2015), sehingga jika subsidi pupuk dikurangi dikhawatirkan akan mengganggu produktivitasnya. Namun di sisi yang lain, alokasi anggaran untuk kebijakan subsidi pupuk sangat besar. Pemerintah Indonesia harus mulai memangkas anggaran subsidi pupuk dan mengalihkannya ke program-program lain terutama terkait investasi di teknologi pertanian. Pengembangan teknologi di sektor pertanian memiliki manfaat lebih besar dan mampu meningkatkan produktivitas dalam jangka panjang ketimbang subsidi pupuk yang begitu-begitu saja tanpa ada perkembangan setiap tahun (Asian Development Bank, 2019).

Subsidi pupuk dinilai masih dibutuhkan karena pupuk mempunyai peranan yang penting bagi peningkatan produksi pertanian. Dalam konteks pembangunan pertanian, pupuk merupakan salah satu unsur penting dan strategis dalam peningkatan produksi dan produktivitas serta menjadi bagian yang tidak terpisahkan dari sistem usahatani (Darwis \& Supriyati, 2013). Dharmveer (2015) melalui penelitiannya juga menyatakan bahwa subsidi pupuk dapat meningkatkan produksi.
Namun, faktanya masih banyak masalah yang terjadi sepanjang subsidi pupuk diberlakukan, seperti kelangkaan pupuk, penyelundupan pupuk ke luar negeri, lonjakan harga di atas HET, perembesan pupuk bersubsidi ke pasar nonsubsidi dan antar wilayah (Kariyasa \& Yusdja, 2005). Masalah lain yang ditimbulkan oleh kebijakan subsidi pupuk, yaitu: distribusi yang tidak adil dan tidak tepat sasaran, dualisme pasar, biaya subsidi yang lebih besar dari manfaat (Susila, 2010). Rizieq (2010) menyebutkan bahwa beberapa penyebab harga pupuk lebih tinggi dari HET adalah lemahnya pengawasan dan selisih antara kebutuhan pupuk di lapangan dengan alokasi.

Badan Kebijakan Fiskal (2017) juga menyebutkan masalah yang muncul akibat terdapat dua pupuk di pasaran (subsidi dan nonsubsidi), di antaranya: pengoplosan pupuk subsidi dan nonsubsidi, penyebaran isu tentang kelangkaan pupuk bersubsidi sehingga harganya mahal, terjadi penimbunan dan penggantian kemasan pupuk subsidi menjadi pupuk tidak disubsidi dan sebagainya. Akibatnya, banyak petani yang belum dapat merasakan manfaat subsidi pupuk secara utuh. Jika membandingkan data antara alokasi 
subsidi pupuk dengan produksi padi di tingkat nasional (Tabel 1), khususnya pada periode 2015-2016, perubahan alokasi anggaran subsidi pupuk hubungannya tidak terlalu linear dengan produksi padi sehingga kebijakan subsidi pupuk tersebut dapat dipertanyakan efektivitasnya.

Tabel 1. Produksi Padi Nasional Tahun 20142018

\begin{tabular}{cccc}
\hline No & Tahun & $\begin{array}{c}\text { Produksi } \\
\text { (ton) }\end{array}$ & $\begin{array}{c}\text { Alokasi Anggaran } \\
\text { Subsidi Pupuk } \\
\text { (triliun rupiah) }\end{array}$ \\
\hline 1 & 2014 & 70.846 .465 & 21,0 \\
2 & 2015 & 75.397 .841 & 31,3 \\
3 & 2016 & 79.354 .767 & 26,9 \\
4 & 2017 & 81.148 .594 & 28,8 \\
5 & 2018 & 83.037 .150 & 33,6 \\
\hline \multicolumn{4}{c}{ Sumber: Kementerian Pertanian RI dan Kementerian } \\
\multicolumn{4}{c}{ Keuangan RI, diolah (2019) }
\end{tabular}

Efektivitas penggunaan pupuk diarahkan pada pemupukan berimbang dan organik sesuai rekomendasi spesifik lokasi atau standar teknis penggunaan pupuk yang dianjurkan. Penerapan pemupukan berimbang perlu didukung dengan aksesbilitas dalam memperoleh pupuk dengan harga yang terjangkau (Kementerian Pertanian, 2020). Kementerian Pertanian membuat kebijakan agar distribusi pupuk bersubsidi dapat memenuhi asas 6 tepat (jumlah, jenis, waktu, tempat, mutu, dan harga) (Jorgi, et al, 2019). Meski demikian, dua dari enam indikator tersebut, yaitu tepat mutu dan tepat jenis tidak digunakan sebagai indikator karena sulit dikuantitatifkan. Menurut Marisa (2011), kebijakan subsidi pupuk berdasarkan keempat indikator tersebut dikategorikan tidak efektif. Namun, Hariningtyas (2014) menyatakan pada penelitiannya bahwa kebijakan subsidi pupuk di Kabupaten Kendal sangat efektif pada indikator tepat waktu.

Kebaruan penelitian ini adalah meneliti efektivitas subsidi pupuk pada tingkat desa, yaitu di Desa Sukaasih dan dengan beberapa variabel yang berbeda. Berdasarkan pemaparan tersebut, penelitian yang membahas tentang efektivitas pelaksanaan kebijakan subsidi pupuk di Desa Sukaasih, Kecamatan Sukatani, Kabupaten Bekasi penting untuk dilaksanakan. Oleh karena itu, penelitian ini bertujuan untuk mendeskripsikan pelaksanaan kebijakan subsidi pupuk di Desa Sukaasih Kecamatan Sukatani Kabupaten Bekasi.

\section{METODE PENELITIAN}

Objek dalam penelitian ini adalah tingkat efektivitas dari penerapan kebijakan subsidi pupuk. Penelitian dilakukan di Desa Sukaasih Kecamatan Sukatani Kabupaten Bekasi. Penentuan lokasi penelitian di Kecamatan Sukatani didasarkan atas pertimbangan dari data 


\section{EFEKTIVITAS KEBIJAKAN SUBSIDI PUPUK DI DESA SUKAASIH \\ KECAMATAN SUKATANI KABUPATEN BEKASI \\ Prasaktiyoga Adiraputra, Dika Supyandi}

sekunder bahwa Kecamatan Sukatani merupakan salah satu wilayah pertanian serta salah satu kecamatan dengan alokasi pupuk bersubsidi terbesar pada tahun 2020 di Kabupaten Bekasi. Pemilihan Desa Sukaasih sebagai lokus penelitian didasari oleh alasan Desa Sukaasih merupakan desa dengan luas sawah terbesar kedua di Kecamatan Sukatani.

Desain penelitian yang digunakan adalah penelitian kuantitatif dengan metode survei. Teknik sampling yang digunakan adalah multistage sampling. Populasi Desa Sukaasih Kecamatan Sukatani berukuran 479 petani. Sampel yang didapatkan dari hasil sampling berukuran 109 petani.

$\begin{array}{ccc}\text { Tujuan } & \text { penelitian } & \text { dianalisis } \\ \text { menggunakan } & \text { analisis } & \text { distribusi }\end{array}$
frekuensi. Efektivitas kebijakan subsidi pupuk dihitung dengan rumus efektivitas pada Tabel 3. Adapun kriteria indikator empat tepat disajikan dalam Tabel 2.

Tabel 2. Kriteria Indikator Empat Tepat

\begin{tabular}{ccl}
\hline No & Indikator & \multicolumn{1}{c}{ Kriteria } \\
\hline 1 & Tepat Harga & Pembelian harus sesuai \\
& & HET yang telah ditetapkan. \\
& & Pupuk urea: Rp1.800/Kg, \\
& & NPK: $\mathrm{Rp} 2.300 / \mathrm{Kg}, \mathrm{SP}-36:$ \\
& & Rp2.000/Kg, ZA: \\
& & $1.400 / \mathrm{Kg}$, Organik : \\
& & Rp500/Kg \\
2 & Tepat Waktu & Harus selalu ada di setiap \\
& & saat petani \\
& & membutuhkannya. \\
3 & Tepat Tempat & Petani harus membeli di \\
& & pengecer resmi yang telah \\
& & ditentukan
\end{tabular}

4 Tepat Jumlah Harus sesuai dengan anjuran jumlah penggunaan pupuk dari pemerintah. Anjuran untuk penggunaan pupuk majemuk NPK, yaitu urea sebanyak $200 \mathrm{~kg} / \mathrm{ha}$ dan NPK sebanyak $300 \mathrm{~kg} / \mathrm{ha}$ atau $200 \mathrm{~kg} /$ ha pupuk urea, $100 \mathrm{~kg} /$ ha pupuk SP-36 dan $100 \mathrm{~kg} /$ ha pupuk NPK yang didasarkan atas PUTS dan kesepakatan penyuluh seKecamatan Sukatani.

Sumber: Arisandi (2016)

Tabel 3. Rumus Efektivitas Distribusi Pupuk Indikator Empat Tepat

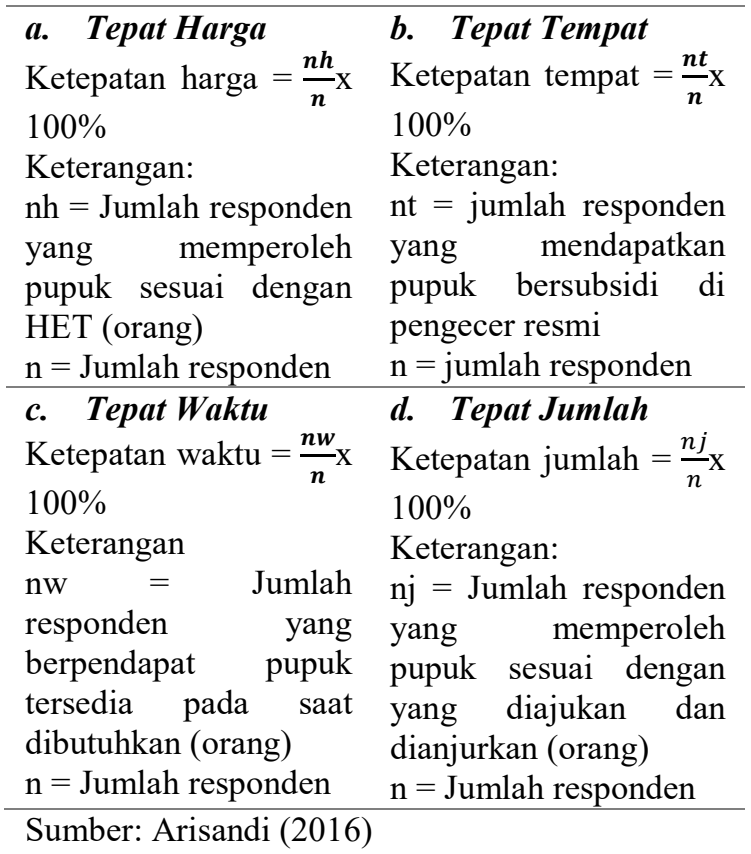

Tabel 4. Kriteria Penilaian Efektivitas

\begin{tabular}{cll}
\hline No & $\begin{array}{c}\text { Interval Persentase } \\
\text { Efektivitas (k) }\end{array}$ & \multicolumn{1}{c}{ Kriteria } \\
\hline 1 & $\mathrm{k} \leq 40 \%$ & Sangat tidak efektif \\
2 & $40 \% \leq \mathrm{k} \leq 60 \%$ & Tidak efektif \\
3 & $60 \% \leq \mathrm{k} \leq 80 \%$ & Cukup Efektif \\
4 & $80 \% \leq \mathrm{k} \leq 90 \%$ & Efektif \\
5 & $90 \% \leq \mathrm{k} \leq 100 \%$ & Sangat Efektif \\
\hline \multicolumn{2}{l}{ Sumber: Arisandi $(2016)$} &
\end{tabular}

Kriteria penilaian efektivitas dihitung per indikator efektivitas. Penghitungan juga dapat dilakukan untuk 
menilai efektivitas secara umum (seluruh indikator) dengan cara merata-ratakan jumlah dari persentase keempat indikator efektivitas.

\section{HASIL DAN PEMBAHASAN}

\section{Pelaksanaan Kebijakan Subsidi Pupuk} di Desa Sukaasih Kecatan Sukatani Kabupaten Bekasi

Kebijakan subsidi pupuk adalah kebijakan yang penting. Seluruh responden menyatakan bahwa telah merasakan manfaat subsidi pupuk sejak lama, bahkan sejak mereka pertama kali melakukan usahatani. Subsidi pupuk juga membantu petani untuk menekan biaya produksi dalam penyediaan pupuk. Apabila dibandingkan dengan penggunaan pupuk nonsubsidi, biayanya akan jauh berbeda.

Tabel 5. Perbandingan Biaya Penggunaan Pupuk Bersubsidi dan Nonsubsidi

\begin{tabular}{ccccc}
\hline No & $\begin{array}{c}\text { Pu- } \\
\text { puk }\end{array}$ & $\begin{array}{c}\text { Dosis } \\
\text { (Kg/ } \\
\text { Ha) }\end{array}$ & $\begin{array}{c}\text { Harga } \\
\text { Subsidi } \\
\text { (Rp/kg) }\end{array}$ & $\begin{array}{c}\text { Harga } \\
\text { Non- } \\
\text { subsidi } \\
\text { (Rp/kg) }\end{array}$ \\
\hline 1 & Urea & 200 & 1.800 & 6.000 \\
2 & NPK & 300 & 2.300 & 9.000 \\
\hline \multicolumn{3}{c}{ Total Harga } & 1.050 .000 & 3.900 .000 \\
\hline \multicolumn{3}{c}{ Selisih Harga } & 2.850 .000 \\
Pupuk Subsidi dan \\
Nonsubsidi \\
\multicolumn{3}{c}{ Sumber: Data primer, diolah (2020) }
\end{tabular}

Berdasarkan Tabel 5 dapat terlihat selisih yang signifikan antara harga pupuk subsidi dan pupuk nonsubsidi. Jika dilihat berdasarkan penggunaan, selisih harganya bahkan mencapai lebih dari $100 \%$. Mengacu pada jumlah penggunaan pupuk spesifik lokasi dari pemerintah, penggunaan pupuk di Desa Sukaasih Kecamatan Sukatani adalah $200 \mathrm{~kg} / \mathrm{ha}$ untuk pupuk urea dan $300 \mathrm{~kg} / \mathrm{ha}$ untuk pupuk NPK. Apabila petani menggunakan pupuk bersubsidi untuk luas lahan satu hektar, maka petani akan mengeluarkan biaya pupuk sebesar Rp1.050.000, sedangkan jika petani menggunakan pupuk nonsubsidi untuk luas lahan satu hektar maka petani akan mengeluarkan biaya sebesar Rp3.900.000. Hal tersebut berarti terdapat selisih Rp2.850.000 antara harga untuk penggunaan pupuk bersubsidi dengan pupuk nonsubsidi. Hal tersebut berarti petani harus membayar 371\% lebih mahal dibandingkan dengan penggunaan pupuk bersubsidi.

Harga pupuk nonsubsidi seringkali melonjak di pasaran. Hal tersebut dapat dimaklumi karena pupuk nonsubsidi merupakan barang bebas yang tanpa pengawasan, tidak seperti pupuk bersubsidi. Kios dapat menentukan sendiri harga jual pupuk nonsubsidi. Pada saat pupuk bersubsidi mengalami keterlambatan suplai atau kelangkaan, petani terpaksa membeli pupuk nonsubsidi yang harganya dapat 
melonjak sewaktu-waktu jika sudah memasuki waktu pemupukan. Akibatnya, petani terpaksa membeli karena tidak ada pilihan lain sehingga petani berpotensi mendapatkan rugi yang cukup besar apabila tidak diimbangi oleh kenaikan harga gabah.

Ketersediaan pupuk di kios harus benar-benar dipastikan agar tidak merugikan petani sehingga petani dapat mengakses pupuk kapanpun sesuai dengan kebutuhannya yang mana hal tersebut merupakan salah satu dari tujuan program subsidi pupuk. Oleh sebab itu, pengajuan maupun perencanaan penggunaan pupuk harus benar-benar sesuai dengan kondisi di lapangan. Besarnya alokasi subsidi biasanya disesuaikan dengan kebutuhan yang diajukan atau Rancangan Definitif Kebutuhan Kelompok (RDKK) yang saat ini sudah dijadikan sistem elektronik menjadi e-RDKK. Pengajuan kebutuhan pupuk bersubsidi disusun oleh petani melalui kelompok tani dan difasilitasi oleh penyuluh lapangan berdasarkan luas lahan yang dimiliki oleh petani. Data RDKK yang telah disusun kemudian diajukan kepada Dinas Pertanian Kabupaten Bekasi oleh BPP Kecamatan Sukatani. Namun, fakta di lapangan menunjukkan bahwa penyusunan RDKK tidak melibatkan petani secara keseluruhan. Penyuluh hanya berkoordinasi dengan ketua kelompok tani untuk menentukan berapa luas lahan yang akan dijadikan dasar untuk pengajuan pupuk bersubsidi. Oleh karena itu, perubahan sistem RDKK menjadi eRDKK merupakan salah satu langkah yang baik karena pengajuan pupuk bersubsidi harus benar-benar sesuai dengan yang dibutuhkan. Sistem eRDKK mengharuskan untuk memasukkan data petani secara lengkap by name by address sehingga penyaluran subsidi pupuk diharapkan lebih tepat sasaran.

Alokasi pupuk bersubsidi dari pemerintah tidak sesuai dengan rencana kebutuhan pupuk yang diajukan pada tahun 2020. Akibatnya realisasi sampai dengan bulan Oktober 2020 mengalami kekurangan. Sehingga pemerintah daerah melalui Dinas Pertanian Kabupaten Bekasi mengajukan penambahan kuota pupuk bersubsidi agar mencukupi hingga Desember 2020. Kondisi seperti ini serupa dengan hasil penelitian Rizieq (2010) yang menunjukan bahwa terdapat selisih antara kebutuhan pupuk di lapangan dengan alokasi sehingga menyebabkan harga pupuk bersubsidi 
yang diterima oleh petani berada di atas HET.

Data yang telah terkumpul pada sistem e-RDKK akan menjadi dasar penentuan alokasi dan penyaluran subsidi pupuk menggunakan instrumen kartu tani. Nantinya, kartu tani akan diproyeksikan menjadi instrumen bagi petani untuk penebusan pupuk bersubsidi. Namun, masih terdapat kendala dalam rencana implementasi kartu tani, khususnya di Kabupaten Bekasi. Salah satu dari kendala tersebut adalah distribusi kartu tani yang belum menyeluruh. Masih banyak petani yang belum mendapatkan kartu tani, padahal sebagian di antaranya sudah mendapatkan kartu tani sejak tahun 2018. Penyebab dari banyaknya petani yang belum menerima kartu tani adalah penyuluh kesulitan mengumpulkan data petani untuk didaftarkan pada sistem eRDKK. Petani sulit untuk memberikan data seperti KTP dan KK karena menganggap persyaratan tersebut berat dan tidak ingin berhubungan dengan perbankan.

Pada saat implementasi kartu tani sebagai instrumen untuk penebusan pupuk bersubsidi, semua petani harus memiliki kartu tani jika ingin menebus pupuk bersubsidi. Jika ada yang belum

mendapatkan kartu tani, tetapi telah terdaftar pada sistem e-RDKK maka diperbolehkan untuk menebus pupuk bersubsidi dengan mengisi formulir tertentu yang harus ditandatangani oleh penyuluh dan kios/pengecer resmi setempat. Jika belum terdaftar pada sistem e-RDKK, maka petani terpaksa tidak diperbolehkan menebus pupuk bersubsidi.

\section{Efektivitas Kebijakan Subsidi Pupuk di Desa Sukaasih Kecamatan Sukatani Kabupaten Bekasi}

\section{1) Tepat Harga}

Indikator tepat harga adalah indikator terpenting dari pelaksanaan kebijakan subsidi pupuk karena harapan dari adanya subsidi pupuk agar petani bisa mendapatkan pupuk dengan lebih mudah dan harga yang terjangkau. Ratarata harga pupuk yang diterima oleh petani tersaji pada Tabel 6 .

Tabel 6. Rata-Rata Harga Pembelian Pupuk

\begin{tabular}{clccc}
\hline No & Uraian & Urea & NPK & SP-36 \\
\hline 1 & $\begin{array}{l}\text { Harga } \\
\text { pembelian } \\
\text { pupuk rata-rata } \\
\text { (Rp/kg) }\end{array}$ & 2.013 & 2.530 & 2.317 \\
2 & $\begin{array}{l}\text { Harga yang } \\
\text { seharusnya } \\
\text { (HET) }(\mathrm{Rp} / \mathrm{kg})\end{array}$ & 1.800 & 2.300 & 2.000 \\
3 & Selisih (Rp/kg) & 213 & 230 & 317 \\
\hline Sumber: Data primer, diolah (2020) & & \\
& $\begin{array}{l}\text { Berdasarkan Tabel } 6 \\
\text { diketahui bahwa }\end{array}$ & data-rata & harga
\end{tabular}


pembelian pupuk bersubsidi berada di atas harga eceran tertinggi. Perbedaan harga pembelian dengan HET disebabkan oleh kios pengecer yang mengambil profit terlalu besar dari pupuk bersubsidi. Hal ini dapat terjadi karena terdapat biaya administrasi jika petani tidak membeli pupuk secara tunai, dan adanya biaya transportasi yang dibebankan kepada petani.

Berdasarkan hasil penelitian, seluruh responden membeli pupuk bersubsidi tidak sesuai dengan HET. Kios atau pengecer yang menjual pupuk bersubsidi secara resmi juga tidak bisa mengikuti aturan HET dalam penjualan pupuk bersubsidi karena terdapat biaya administrasi jika petani membeli pupuk tidak secara tunai. Selain itu, juga terdapat biaya transportasi yang dibebankan kepada petani. Adnyana dan Mokhtar (2019) juga menyatakan bahwa harga pupuk bersubsidi yang diterima oleh petani berbeda dari yang ditetapkan. Harga rata-rata pembelian pupuk bersubsidi di Malawi juga berada di atas harga yang seharusnya karena ada petani yang membeli dengan harga penuh atau tidak mendapatkan kupon pupuk bersubsidi (Holden \& Lunduka, 2010).

Petani di Desa Sukaasih tidak mengetahui tentang aturan HET. Hal ini menyebabkan petani menerima berapapun harga yang ditetapkan di kios sehingga kenaikan harga dianggap sebagai hal yang wajar khususnya jika terjadi kondisi-kondisi tertentu seperti kelangkaan. Oleh karena itu, hampir semua responden menganggap bahwa harga pupuk yang diterima telah sesuai dengan harapan. Sebanyak 95\% dari total responden mengatakan bahwa harga pupuk yang diterima telah sesuai dengan harapan mereka, sedangkan sisanya berharap harga pupuk dapat sesuai dengan HET.

\section{2) Tepat Jumlah}

Gambar 2 menunjukkan banyaknya petani yang sudah menerapkan rekomendasi dosis pemupukan dan yang belum melaksanakan rekomendasi dosis pemupukan.

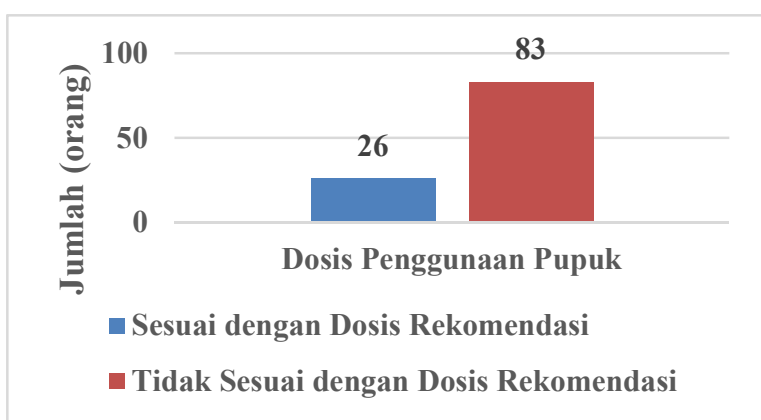

\section{Gambar 1. Diagram Indikator Tepat Jumlah Penggunaan Pupuk (orang) Sumber: Data primer, diolah (2020)}

Berdasarkan Gambar 2, hanya $23,85 \%$ dari total responden yang sudah melakukan pemupukan sesuai rekomendasi dosis yang telah ditentukan, 
sedangkan $76,15 \%$ masih belum melakukan pemupukan sesuai dengan rekomendasi dosis yang telah ditentukan. Jumlah penggunaan pupuk pada setiap jenisnya bervariasi, ada yang di bawah rekomendasi maupun di atas rekomendasi. Hasil ini sesuai dengan penelitian Gulati dan Banerjee (2015) yang menyatakan bahwa kebijakan subsidi pupuk di India menyebabkan penggunaan pupuk yang berlebihan dan dapat menyebabkan berbagai masalah.

\section{3) Tepat Tempat}

Indikator tepat tempat mengharuskan petani untuk membeli pupuk bersubsidi di kios atau pengecer resmi yang telah ditunjuk oleh distributor pupuk untuk menyalurkan pupuk bersubsidi di wilayahnya. Hasil penelitian dari indikator tepat tempat disajikan pada Tabel 7.

Tabel 7. Persentase Indikator Tepat Tempat

\begin{tabular}{clrr}
\hline No & $\begin{array}{c}\text { Tempat } \\
\text { Pembelian }\end{array}$ & $\begin{array}{c}\text { Jumlah } \\
\text { (responden) }\end{array}$ & $\begin{array}{c}\text { Persentase } \\
\text { (\%) }\end{array}$ \\
\hline 1 & $\begin{array}{l}\text { Kios/pengecer } \\
\text { resmi } \\
2\end{array}$ & 109 & 100 \\
& $\begin{array}{l}\text { Bukan } \\
\text { kios/pengecer } \\
\text { resmi }\end{array}$ & 0 & 0 \\
\hline & Jumlah & $\mathbf{1 0 9}$ & $\mathbf{1 0 0}$ \\
\hline
\end{tabular}

Sumber: Data primer, diolah (2020)

Berdasarkan Tabel 7, seluruh responden membeli pupuk bersubsidi di pengecer resmi yang telah ditentukan. Petani membeli pupuk bersubsidi di lokasi terdekat yaitu Kios Dian Jaya yang terletak di Desa Sukahurip. Kios Dian Jaya memang ditentukan untuk menjadi tempat pembelian pupuk bersubsidi bagi petani di tiga desa, yaitu Desa Sukaasih, Desa Sukahurip, dan Desa Banjarsari. Secara keseluruhan, responden penelitian mengatakan bahwa Kios Dian Jaya lokasinya sudah cukup dekat dengan lokasi rumah atau sawah mereka dan tidak menyulitkan dalam segi akses maupun transportasi.

Hasil ini sesuai dengan penelitian yang dilakukan oleh Zulaiha, et al (2018) yang menyebutkan bahwa secara umum di tingkat nasional efektivitas pada indikator tepat tempat dapat dikatakan efektif, meskipun terdapat satu provinsi yang dikategorikan tidak efektif dalam hal tepat tempat, yaitu Provinsi Kepulauan Riau. Hal tersebut disebabkan oleh kondisi geografis Provinsi Kepulauan Riau yang menyulitkan proses distribusi pupuk bersubsidi sehingga indikator tepat tempat hanya mencapai $30,88 \%$. Namun, terdapat perbedaan dengan hasil penelitian Mustapha, et al (2016) di Ghana yang menyatakan bahwa terdapat petani yang tempat tinggal atau lokasi usahataninya jauh dari tempat distribusi pupuk bersubsidi sehingga tidak mendapatkan akses. 


\section{EFEKTIVITAS KEBIJAKAN SUBSIDI PUPUK DI DESA SUKAASIH \\ KECAMATAN SUKATANI KABUPATEN BEKASI \\ Prasaktiyoga Adiraputra, Dika Supyandi}

\section{4) Tepat Waktu}

Gambar 3 menunjukkan banyaknya petani yang sudah mendapatkan pupuk bersubsidi tepat pada saat mereka membutuhkan/membelinya.

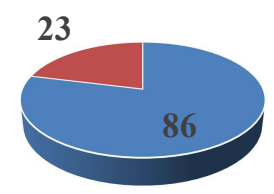

- Pupuk selalu ada pada saat dibutuhkan

- Pupuk tidak tersedia pada saat dibutuhkan

Gambar 2. Diagram Indikator Tepat Waktu Sumber: Data primer, diolah (2020)

Sebanyak 86 responden atau 78,9 persen dari total seluruh responden mengatakan bahwa mereka mendapatkan pupuk pada saat dibutuhkan. Hal tersebut berarti tingkat efektivitas pada indikator tepat waktu dapat dikategorikan efektif. Hasil ini berbeda dengan hasil penelitian yang dilakukan oleh Hariningtyas (2014) di Kabupaten Kendal yang menyebutkan bahwa efektivitas subsidi pupuk pada indikator tepat waktu dikategorikan sangat efektif dengan persentase $100 \%$. Petani di Kabupaten Kendal tidak mengalami kesulitan dalam mengakses pupuk bersubsidi dan semua petani mendapatkan pupuk bersubsidi pada saat dibutuhkan.
Tabel 8. Persentase Efektivitas Kebijakan Subsidi Pupuk di Desa Sukaasih

\begin{tabular}{|c|c|c|c|c|}
\hline No. & Indikator & $\begin{array}{l}\text { Tepat } \\
(\%)\end{array}$ & $\begin{array}{l}\text { Tidak } \\
\text { Tepat } \\
(\%)\end{array}$ & $\begin{array}{l}\text { Jumlah } \\
(\%)\end{array}$ \\
\hline 1 & $\begin{array}{l}\text { Tepat } \\
\text { Harga }\end{array}$ & 0 & 100 & 100 \\
\hline 2 & $\begin{array}{l}\text { Tepat } \\
\text { Jumlah }\end{array}$ & 23,85 & 76,15 & 100 \\
\hline 3 & $\begin{array}{l}\text { Tepat } \\
\text { Tempat }\end{array}$ & 100 & 0 & 100 \\
\hline 4 & $\begin{array}{l}\text { Tepat } \\
\text { Waktu }\end{array}$ & 78,90 & 21,10 & 100 \\
\hline & Rata-rata & 50,69 & 49,31 & 100 \\
\hline
\end{tabular}

Sumber: Data primer, diolah (2020)

Berdasarkan Tabel 8, diketahui bahwa tingkat efektivitas secara keseluruhan adalah 50,69\% yang dapat dikategorikan tidak efektif. Ketidakefektifan tersebut disebabkan oleh indikator tepat harga dan tepat jumlah. Hasil ini sesuai dengan penelitian Fearon, et al (2015) yang menyebutkan bahwa program subsidi pupuk di Ghana tidak efektif dan efisien meskipun memiliki alokasi anggaran yang besar.

Tidak efektifnya kebijakan subsidi pupuk di Desa Sukaasih disebabkan oleh pengawasan yang belum terlalu optimal. Instansi terkait harus lebih ketat mengawasi pelaksanaan kebijakan subsidi pupuk di lapangan agar tujuan subsidi dapat tercapai sepenuhnya dan tidak merugikan petani.

Semua petani menyatakan bahwa mereka sangat terbantu dengan adanya kebijakan subsidi pupuk. Kebutuhan pupuk menjadi terjamin terjangkau, 
terutama jika dibandingkan dengan harus membeli pupuk nonsubsidi yang harganya berada jauh di atas pupuk bersubsidi. Petani berharap kebijakan subsidi pupuk tetap dilanjutkan.

\section{KESIMPULAN DAN SARAN}

\section{Kesimpulan}

Kebijakan subsidi pupuk di Desa Sukaasih Kecamatan Sukatani Kabupaten Bekasi jika ditinjau dari empat indikator dapat disimpulkan tidak berjalan efektif karena petani membeli pupuk bersubsidi sesuai dengan harga yang lebih tinggi dibandingkan dengan harga yang telah ditetapkan. Selain itu, penggunaan pupuk bersubsidi dalam budidaya masih tidak sesuai dengan rekomendasi dosis pemberian pupuk pada padi yang telah ditentukan.

\section{Saran}

Pemerintah harus memastikan percepatan dan mitigasi hambatan implementasi kartu tani di daerah. Implementasi penyaluran dan penggunaan pupuk bersubsidi harus diperketat dengan kolaborasi dari pihak-pihak terkait agar penerima dan pemakaian pupuk bersubsidi dapat efektif, tepat sasaran, dan tepat guna. Kekurangan dari penelitian ini adalah tidak turut mengkaji tentang implementasi kartu tani karena masih dalam tahap persiapan di Kabupaten Bekasi. Rekomendasi untuk penelitian lebih lanjut adalah mengkaji mengenai efektivitas implementasi kartu tani karena kartu tani akan digunakan sebagai syarat petani untuk memperoleh pupuk bersubsidi.

\section{DAFTAR PUSTAKA}

Adnyana, I. P., \& Mohktar, M. S. (2019). Optimalisasi Kinerja Sistem Distribusi Pupuk Bantuan Pemerintah di Provinsi NTB. SOCA: Jurnal Sosial Ekonomi Pertanian, 13(2), 201-217.

Arisandi, N. W. (2016). Efektivitas Distribusi Subsidi Pupuk Organik dan Dampaknya terhadap Pendapatan Usahatani Padi Sawah di Subak Sungsang, Desa Tibubiu, Kabupaten Tabanan. Jurnal Agribisnis dan Agrowisata 5(1), 110.

Asian Development Bank. (2019). Polices to Support Invesment Requirements of Indonesia's Food and Agriculture Development During 2020-2045. Manila: Asian Development Bank.

Badan Kebijakan Fiskal. (2017). Seri Analisis Kebijakan Fiskal: Dinamika Kebijakan Subsidi Pupuk dan Ketahanan Pangan. Jakarta: PT Gramedia Pustaka Utama.

Badan Pusat Statistik Jawa Barat. (2020). Provinsi Jawa Barat dalam Angka 2020. Bandung: Badan Pusat Statistik Provinsi Jawa Barat.

Darwis, V., \& Supriyati. (2013). Subsidi Pupuk: Kebijakan, Pelaksanaan, dan Optimalisasi Pemanfaatannya. 
Analisis Kebijakan Pertanian, 11(1), 45-60.

Dharmveer. (2015). Fertilizer Subsidy in India. International Research Journal of Management Sociology and Humanity, 6(12), 98-106.

Fearon, J., Adraki, P. K., \& Boateng, V. F. (2015). Fertilizer Subsidy Programme in Ghana: Evidence and Performance after Six Years of Implementation. Journal of Biology, Agriculture, and Healthcare, 5, 100-107.

Gulati, A., \& Banerjee, P. (2015). Rasionalising Fertiliser Subsidy in India: Key Issues and Policy Option. New Delhi: Indian Council for Research on International Economic Relations.

Hariningtyas, F. C. (2014). Pengaruh Efektivitas Subsidi Pupuk terhadap Produksi Padi di Kabupaten Kendal. [Skripsi]. Surakarta: Fakultas Pertanian Universitas Sebelas Maret Surakarta.

Hartatik, W., Husnain, \& Widowati, L. R. (2015). Peranan Pupuk Organik dalam Peningkatan Produktivitas Tanah dan Tanaman. Jurnal Sumber Daya Lahan, 9(2), 107120.

Holden, S., \& Lunduka, R. (2010). Impacts of the Fertilizer Subsidy Programme in Malawi: Targeting, Household Perceptions and Preferences. Norway: Department of International Environment and Development Studies, Norwegian University of Life Sciences.

Jorgi, R. S., Gayatri, S., \& Dalmiyatun, T. (2019). Hubungan Tingkat Pengetahuan Petani dengan Efektivitas Pelaksanaan Program Kartu Tani di Kabupaten Semarang. AGRARIS: Journal of Agribusiness and Rural Development Research 5(2), 88-98.
Kariyasa, I. K., \& Yusdja, Y. (2005). Evaluasi Kebijakan Sistem Distribusi Pupuk Urea di Indonesia: Kasus Provinsi Jawa Barat. Analisis Kebijakan Pertanian, 3(3), 201216.

Kementerian Keuangan RI. (2020). Alokasi Anggaran Kedaulatan Pangan. Diambil kembali dari Portal Data APBN Kementerian Keuangan RI: http://www.dataapbn.kemenkeu.go.id/Dataset/Detai 1s/1015

Kementerian Pertanian RI. (2019). Data Lima Tahun Terakhir Subsektor Tanaman Pangan. Diambil kembali dari Website Kementerian Pertanian:

pertanian.go.id/Data5tahun/TPATA P-2017(pdf)/20-ProdPadi.pdf

Kementerian Pertanian RI. (2020). Petunjuk Teknis Pelaksanaan Penyediaan dan Penyaluran Pupuk Bersubsidi TA 2020 (Revisi). Jakarta: Direktorat Jenderal Prasarana dan Sarana Pertanian Kementerian Pertanian.

Marisa, S. (2011). Analisis Efektivitas Kebijakan Subsidi Pupuk dan Pengaruhnya terhadap Produksi Padi (Studi Kasus: Kabupaten Bogor). [Skripsi]. Bogor: Fakultas Ekonomi dan Manajemen Institut Pertanian Bogor.

Mustapha, S., Abdulai, I. A., \& Urtarz, Y. (2016). Evaluating the Determinants of Access to Ghana Fertilizer Subsidy Program. Asian Journal of Agricultural Extension, Economics \& Sociology, 11(3), 111.

Rizieq, R. (2010). Dampak Subsidi Pupuk terhadap Kesejahteraan Petani. SOCA: Jurnal Sosial Ekonomi Pertanian, 10(2), 121133.

Susila, W. R. (2010). Kebijakan Subsidi Pupuk: Perlu Ditinjau Kembali. 
Jurnal Litbang Pertanian 29(2), 43-49.

Zulaiha, A. R., Nurmalina, R., \& Sanim, B. (2018). Kinerja Subsidi Pupuk di Indonesia. Jurnal Aplikasi Manajemen dan Bisnis, 4(1), 271283. 